\title{
Limb-Specific Representation for Reaching in the Posterior Parietal Cortex
}

\author{
Steve W. C. Chang, Anthony R. Dickinson, and Lawrence H. Snyder \\ Department of Anatomy and Neurobiology, Washington University School of Medicine, St. Louis, Missouri 63110
}

To reach for something we see, the brain must integrate the target location with the limb to be used for reaching. Neuronal activity in the parietal reach region (PRR) located in the posterior parietal cortex represents targets for reaching. Does this representation depend on the limb to be used? We found a continuum of limb-dependent and limb-independent responses: some neurons represented targets for movements of either limb, whereas others represented only contralateral-limb targets. Only a few cells represented ipsilateral-limb targets. Furthermore, these representations were not dependent on preferred direction. Additional experiments provide evidence that the PRR is specifically involved in contralateral-limb movements: firing rates are correlated with contralateral- but not ipsilateral-limb reaction times. The current study therefore provides novel evidence that the PRR operates as a limb-dependent stage that lies further along the sensory-motor transformation for visually guided reaching than previously expected.

Key words: posterior parietal cortex; motor planning; parietal reach region; monkey; electrophysiology; spatial processing

\section{Introduction}

To reach for something that we see, the spatial location of the target must be encoded by the brain and a signal based on this information must then be transmitted to the muscles. Target location is received by the retina and transmitted to the visual cortex, where it is encoded in a retinocentric frame of reference. For visually guided reaching, however, this spatial information must be transformed to a joint or muscle-based frame of reference (i.e., a limb-dependent representation). The activity of neurons in the posterior parietal cortex (PPC) and the premotor cortex (PM) is consistent with their possible involvements in transforming target representation from sensory (limb independent) into motor (limb dependent) coordinates (Andersen et al., 1997; Galletti et al., 1997; Kalaska et al., 1997; Wise et al., 1997; Hoshi and Tanji, 2000; Cisek et al., 2003; Medendorp et al., 2005). Many neurons in the parietal reach region (PRR) in PPC encode the spatial location of targets for reaches (Snyder et al., 1997; Calton et al., 2002). However, it is not known whether the reach target representation of PRR is limb independent or if it depends on the limb to be moved (limb dependent). This distinction of whether this spatial representation is limb specific or not is critical for understanding the flow of information in the brain and the mechanisms of motor control.

The PRR is located in and around the intraparietal sulcus (IPS), close to the junction with the parieto-occipital sulcus (POS) (Snyder et al., 1997). It lies primarily on the medial bank of

\footnotetext{
Received Dec. 26, 2007; revised April 30, 2008; accepted May 1, 2008.

This work was supported by the National Institutes of Health. We thank J. J. Vytlacil and J. T. Baker for assistance with MR imaging for anatomical localizations and V. Rao for helpful comments on this manuscript.

Correspondence should be addressed to Steve W. C. Chang, Department of Anatomy and Neurobiology, Washington University School of Medicine, 660 South Euclid Avenue, Box 8108, St. Louis, M0 63110. E-mail: steve@eye-hand.wustl.edu.

D0I:10.1523/JNEUROSCI.1442-08.2008

Copyright $\odot 2008$ Society for Neuroscience $\quad 0270-6474 / 08 / 286128-13 \$ 15.00 / 0$
}

the IPS and the anterior bank of POS but also extends into a portion of the lateral bank (Calton et al., 2002). It likely overlaps portions of the medial intraparietal area (MIP) (Colby et al., 1988; Colby and Duhamel, 1991), the posterior occipital area (PO) (Lewis and Van Essen, 2000a), the dorsal part of PO (V6a) (Galletti et al., 1999), and perhaps the caudal intraparietal sulcus/ lateral occipitoparietal area (Sakata et al., 1998; Lewis and Van Essen, 2000b). PRR cells respond to both spatial information (i.e., target location) and nonspatial information (i.e., effector instruction; arm versus eye movement) about upcoming arm movements to both visual and auditory targets (Cohen and Andersen, 2000; Cohen et al., 2002). Moreover, activity that is measured immediately before the presentation of a spatial target is correlated with subsequent visually guided reach reaction times (RTs) (but not saccade RTs) on a trial-by-trial basis, which is consistent with a functionally significant role in reaching (Snyder et al., 2006).

The PRR projects directly to the ipsilateral dorsal premotor cortex (PMd) (Tanne et al., 1995; Johnson et al., 1996; Wise et al., 1997), where the majority of cells are tuned for both contralateral- and ipsilateral-limb movements with a stronger representation for preparing to move the contralateral limb (Kermadi et al., 1998; Hoshi and Tanji, 2000, 2006; Cisek et al., 2003). The PMd projects, in turn, to the primary motor cortex (M1), which contains cells that are strongly biased for contralaterallimb movements (Muakkassa and Strick, 1979; Cisek et al., 2003). It is unknown whether PRR cells provide limb-independent or limb-dependent information to PMd cells. In this study, we compared neuronal activity during contralateral- and ipsilateral-limb trials to determine the limb specificity of PRR neurons. To address the functional significance of the PRR with respect to planning movements with different limbs, we also correlated PRR activity levels with the RTs of contralateral- and ipsilateral-limb movements. 


\section{Materials and Methods}

Two male Rhesus monkeys (Macaca mulatta) were trained to make eye and arm movements to visible and remembered targets. All procedures conformed to the Guide for the Care and Use of Laboratory Animals and were approved by the Washington University Institutional Animal Care and Use Committee.

Eye position was monitored by the scleral search coil technique (CNC Engineering). Arm position was monitored by a $43.2 \mathrm{~cm}$ touch panel (Keytec) with custom electronics to minimize electrical interference and improve temporal resolution $(8 \mathrm{~ms})$. The animals sat in a customdesigned monkey chair (Crist Instrument) with a fully open front for unimpaired reaching movements. On separate blocks of trials, either the left or right limb was used for reaching, with the other limb prevented from touching the screen by one of two adjustable Plexiglas panels. Visual stimuli were back-projected by a cathode ray tube projector in complete darkness onto a touch panel, which was mounted vertically $25 \mathrm{~cm}$ in front of the animal. Cells were recorded from the right hemisphere in both monkeys.

Three separate experiments were performed. In the first experiment, we compared neuronal responses to reaches performed with the right versus the left limb to a remembered target location (see Figs. 1-3, 5-7). In the second experiment, we compared the tuning curves of right and left limb movements (see Fig. 4). In the final experiment, we tested for a correlation between firing rate and movement RTs (see Figs. 8, 9). We first describe our general methodology, followed by details of each experiment.

All three experiments involved variations on center-out reaching and saccade tasks. All trials began with the eyes fixating at a central target, and the arm to be used in that block touching that same central target. On center-out memory-guided reach trials, the eyes had to remain within $3^{\circ}$ of the central target while the hand moved to within $8.5^{\circ}$ of the remembered location of the peripheral target. On center-out memory-guided saccade trials, the hand had to remain within $6^{\circ}$ of the central fixation target while the eyes moved to within $7.5^{\circ}$ of the remembered location of the peripheral target. In addition to these absolute windows, a smaller relative position window $\left(\sim 3^{\circ}\right)$ was enforced around the animal's initial eye and arm locations. After 150-200 ms from the target acquisition by eyes or arm, the target was reilluminated for 100-150 ms to provide feedback about movement accuracy to the animals. Errors (failure to achieve or maintain fixation or touch within the absolute or relative windows, premature or inaccurate movements) resulted in immediate termination of the trial followed by a short $(0.5-1.5 \mathrm{~s})$ time out, and the trial was excluded from analysis.

Experiments 1 and 2 began by choosing the right or left limb at random, isolating a cell and then mapping the directional tuning curve of that cell (directional mapping task), all using the same limb. Mapping was done using center-out, combined eye and arm movements to visible targets with no delay. Neurons in PRR show similar preferred directions under these conditions as for delayed, memory-guided reach tasks, but the visually guided eye and arm task is easier and faster (our unpublished observations). Each trial began with the eyes and selected hand at the central target (gray square, $0.9 \times 0.9^{\circ}$, in visual degrees). After $400 \mathrm{~ms}$ the central fixation target was extinguished and one of eight peripheral targets appeared (blue square, $1.5 \times 1.5^{\circ}$ ) at $20^{\circ}$ eccentricity. The animal was rewarded for moving the eyes and arm to within the specified window of the visible target ( $5-6^{\circ}$ for arm and $4-5^{\circ}$ for eye). The peripheral target associated with the greatest evoked activity was chosen on-line as the "preferred direction" and the opposite direction constituted the "null direction."

Experiment 1: Limb specificity. To compare planning and execution of reaching movements with the right versus left forelimb, we obtained four blocks of interleaved preferred and null direction memory reach and saccade trials (see Fig. 1A). The first block used the same limb as in the directional tuning task. For the next three blocks, the reaching limb was alternated in A-B-A-B manner. Each block consisted of 10 trials of each type, for a total of 40 trials. Five hundred $\mathrm{ms}$ after touching and fixating at the central target (gray square, $0.9 \times 0.9^{\circ}$ ), a peripheral target (green or red square signifying reach or saccade trials, $2.4 \times 2.4^{\circ}$ ) appeared for 300 ms and was then extinguished. After a memory period of $800 \mathrm{~ms}$ (in darkness without any stimulus on the screen), the central fixation target was extinguished to signal the animal to move to the remembered target location. On saccade trials, the arm remained at the central fixation point; on reach trials, the eyes remained at the central fixation point. Saccade trials were included to confirm that these cells were more active during the planning of reaches compared with saccades, and to serve as a control condition between two different limb blocks.

Experiment 1 was conducted on 175 cells from two monkeys, with cells selected by virtue of showing spatially tuned responses in the mapping task. After recording was completed, we tested for any change in isolation across the four blocks by comparing modulation in the two contralateral blocks and in the two ipsilateral blocks. If either pair of blocks showed a statistical difference in memory-period modulation $(p<0.01$, twosided $t$ test), then all the data from that cell were discarded. The data from 28 cells were discarded because the recorded responses were not consistent across blocks of the same limb condition, although including these 28 cells does not alter our basic conclusions. We were specifically interested in cells with responses temporally linked to the presentation of a visual stimulus that were sustained throughout the memory period ("memory activity"), because these are the cells most likely to be processing visual spatial information for the purposes of movement planning. We therefore tested for spatially tuned modulation shortly after peripheral target onset ("visual period," 50-300 ms after target onset; preferred direction $>$ null direction response, one-sided $t$ test, $p<0.05)$ and during the putative movement-planning period (450-950 ms after target onset; preferred direction $>$ null direction response, one-sided $t$ test). A total of 107 cells $(73 \%$ of those whose responses were stable across the four blocks) met the first inclusion criterion, and a partially overlapping set of 107 met the second criterion. Ninety cells (61\%) met both criteria (monkey G, 60 cells; monkey I, 30 cells).

In addition to the visual interval (50-300 ms after target onset) and memory interval (450-950 ms after target onset), we also measured activity during a movement interval ( $100 \mathrm{~ms}$ before movement onset to 250 $\mathrm{ms}$ after movement onset) and a baseline interval ( $400 \mathrm{~ms}$ interval before target onset to $25 \mathrm{~ms}$ after target onset). Within these intervals, we computed firing rates using raw spike counts, not smoothed data. We calculated a limb-specificity index for each cell as a contrast ratio for the different intervals using the following equation:

(modulation on contralateral limb trials) - (modulation on ipsilateral limb trials) $\overline{\text { (modulation on contralateral limb trials) }+ \text { (modulation on ipsilateral limb trials) }}$,

where modulation was defined as the difference in activity on trials involving a preferred direction reach and a reach in the opposite direction. By taking this difference, we isolated the direction-specific effects of planning and executing a reach from differences in baseline firing caused by, for example, the different postures in the two types of blocks. Effector specificity was computed for each cell by subtracting the memory-period modulation on saccade trials from memory-period modulation on reach trials.

For measuring neuronal response latencies, the number of spikes observed in consecutive $1 \mathrm{~ms}$ bins were smoothed using a 181-point digital low-pass filter with a transition band spanning $2-15 \mathrm{~Hz}$. The response latency to a visual target was identified as the first of at least 50 consecutive $1 \mathrm{~ms}$ bins in which the mean activity on preferred trials exceeded the mean activity on null trials by at least three SEs.

Experiment 2: Spatial tuning. To compare the full directional tuning curves of reaches made with the contralateral versus ipsilateral limbs, we recorded the responses of 45 neurons on trials in which animals made $20^{\circ}$ center-out combined eye and arm movements to each of 16 peripheral targets. The task was identical to the directional mapping task used in experiment 1 except that 16 rather than 8 targets were used. Animals performed 160 trials ( 10 repetitions to each target) using one limb, chosen at random, followed by 160 trials using the other limb. We averaged firing across trials in the interval $150-300 \mathrm{~ms}$ after target onset separately for ipsilateral and contralateral reach trials, and fit those values to a three-parameter cosine tuning curve. The cosine tuning curve was considered to fit the data if the fitting algorithm ("nls" function from the R statistical package) converged to a solution with a modulation amplitude 
that was significantly greater than zero $(p<0.025)$. This $p$ value meant that the false positive rate for being tuned for at least one limb was $5 \%$. To test if the phases of the cosine fits (the preferred directions) were significantly different for ipsilateral and contralateral reach trials, we performed a bootstrap analysis. We resampled our data with replacement (within, not across, trial types) and calculated a new phase difference. We repeated this 1000 times, determined the $95 \%$ confidence interval for the phase difference, and asked if this confidence interval included $0^{\circ}$.

Experiment 3: Functional significance. To compare firing rate with reach RT, the activities of a subset of cells from experiment 1 were recorded during two blocks of a cue-delay-target task using different limbs (see Fig. 8). In this task, 500-800 ms after touching and fixating at the central target $\left(1.5 \times 1.5^{\circ}\right)$, the central target changed from white to either red or green, cueing an upcoming reach or saccade, respectively. After a second delay of 600,900 , or $1200 \mathrm{~ms}$, a gray target $\left(1.5 \times 1.5^{\circ}\right)$ appeared at one of eight equally spaced positions, located $20^{\circ}$ from the central fixation target. Animals executed the previously cued movement as soon as the peripheral target appeared.

Firing rates in the last $300 \mathrm{~ms}$ before peripheral target onset in each individual trial were correlated with the corresponding reach or saccade RT. RT was defined as the time from the appearance of the peripheral target to movement initiation. Movement initiation was defined as the moment that the hand either broke contact with the touch screen or moved at least $2.5^{\circ}$. Additional details can be found in the study by Snyder et al. (2006).

Anatomical localization. To guide the placement of our recording tracks and to localize recording sites, we acquired high-resolution magnetic resonance images (MRIs) of monkey's brains and recording chambers before data collection, using methods described previously (Calton et al., 2002). Briefly, each animal was anesthetized and a surface coil was positioned around the chamber. A 3T Siemens MRI scanner running a magnetization-prepared rapid-acquisition gradient echo sequence was used to obtain a high resolution $(0.5 \times 0.5 \times 0.5 \mathrm{~mm})$ structural scan. To localize our recording sites, we placed a custom-designed cylinder containing MR contrast agent (gadoversedamide) into the recording chamber. Vertical bars inside the cylinder at known locations displaced the contrast agent, allowing us to reconstruct the position and orientation of the recording chamber and grid relative to the cortex. In several scanning sessions, we injected $100 \mu \mathrm{l}$ of $0.1 \mathrm{~mol} / \mathrm{L}$ manganese in monkey $\mathrm{G}$ at known coordinates. By visualizing this injection in the scan, we determined the accuracy of our localization method to be $1-2 \mathrm{~mm}$.

To test for anatomical clustering of limb-independent and limbdependent cells, we used principle component analysis to identify the axis, within three-dimensional space, along which cells were most dispersed. We then projected cells to that axis and used a Wilcoxon signed rank test to test whether limb-independent and limb-dependent cells were clustered differently along that axis.

\section{Results}

\section{Behavioral performance}

To determine whether PPR may play a lateralized role in planning reaches, monkeys performed memory-guided reaching movements using either the contralateral or ipsilateral limb (memory task) (Fig. 1A). The animals were well practiced in the task and performed quickly and at high success rates (Table 1, memory task). The values shown represent performance during the collection of single neuron data. Because the memory interval was fixed at $800 \mathrm{~ms}$, animals could anticipate the go cue, resulting in reaction times of $200 \mathrm{~ms}$ or less. Success rates were generally high.

\section{Single-unit activity}

We recorded from 175 cells during the memory reach task. Onehalf of the cells were isolated and first tested during contralaterallimb movements, and the other half during ipsilateral-limb movements. Four blocks of memory reaches were performed, alternating limbs with each block. The data from 28 cells were discarded because the recorded responses were not consistent across blocks of the same limb condition (see Materials and Methods), although including these 28 cells did not alter our basic conclusions. Of the remaining 147 cells, 90 (61\%) showed statistically significant visual- and memory-period neuronal modulation (monkey G, 60 of 85 cells; monkey I, 30 of 62 cells) (see Materials and Methods) and thereby met our inclusion criteria for this study. Twenty-three cells did not show significant modulation in either period, 17 showed only visual-period activity, and another 17 showed only memory-period activity.

As in previous studies, we found that cells in PRR were modulated more strongly before a planned reaching movement than before a planned saccadic eye movement (Snyder et al., 1997; Calton et al., 2002). Effector specificity was quantified by subtracting memory-period modulation on saccade trials from memory-period modulation on reach trials, and was found to be significantly positive (greater for reaches than saccades) at the entire population level ( 147 cells; $p<0.00001$ paired two-sided $t$ test). At the individual cell level, 74 of 147 cells showed significantly $(p<0.05)$ more activity on reach compared with saccade trials, and only four cells showed the reverse effect (saccade greater than reach). This difference between reach and saccade trial modulation was greater during contralateral-limb blocks (abscissa) than ipsilateral-limb blocks (ordinate) (Fig. $1 B$ ). This was true for the entire population of 147 cells (Fig. $1 B$, light plus dark points) ( $p<0.05$, paired Wilcoxon signed rank test), as well as for the subset of 90 cells with visual- and memory-period modulation (dark points) $(p<0.0005)$.

We found individual cells with both limb-independent and limb-dependent representations. Data from a limb-independent cell are shown in Figure 1C. Memory-period activity $(500 \mathrm{~ms}$ interval starting $450 \mathrm{~ms}$ after target onset) was statistically indistinguishable on contralateral- and ipsilateral-limb trials $(17.50 \pm$ 1.56 vs $16.00 \pm 1.28$ spikes/s, mean $\pm \mathrm{SEM}$; two-sided $t$ test, $p=$ 0.47). Activity occurring around the time of the movement of either limb (150 ms interval starting $100 \mathrm{~ms}$ before movement onset) was also indistinguishable $(20.57 \pm 1.49$ vs $18.86 \pm 1.88$ spikes/s; $p=0.48)$. This cell is an example of a bilateral-limb cell (see below). In contrast, other cells (Fig. 1D) were much more active on contralateral- compared with ipsilateral-limb trials (memory-period activity, $15.70 \pm 1.66$ vs $3.70 \pm 0.93$ spikes/s, $p<0.00001$; movement activity, $15.29 \pm 1.58$ vs $5.29 \pm 0.78$ spikes/s, $p<0.00001)$. In fact, the memory-period activity of this particular cell on ipsilateral-limb trials was indistinguishable from the baseline level $(3.70 \pm 0.93$ vs $3.62 \pm 0.47$ spikes $/ \mathrm{s} ; p=$ 0.94). This cell is a clear example of a contralateral-limb cell.

\section{Limb specificity of PRR population}

We first compared the neuronal activity before target onset to see whether baseline firing was affected by which arm was being used. Fifty-three PRR cells (59\%) showed a significant difference in baseline firing (400 ms before target onset to $25 \mathrm{~ms}$ after target onset) during contralateral-limb versus ipsilateral-limb reaching blocks ( $p<0.05$, two-sided $t$ test) (Fig. $2 A$, red bars). Of these 53 cells, 30 showed higher firing on contralateral-limb blocks and 23 showed higher firing on ipsilateral-limb blocks. At the population level, there was no generalized limb-related bias before target onset $(11.73 \pm 1.10$ spikes/s on contralateral blocks vs $11.45 \pm$ 1.13 spikes/s on ipsilateral blocks, for a mean difference of $0.21 \pm$ $0.80 ; p=0.35$ ) (Fig. $2 A$ ).

Next, we examined modulation during the memory period (450-950 ms after target onset). We defined modulation as the difference in activity on trials involving a preferred direction reach and a reach in the opposite direction. By defining modula- 
A
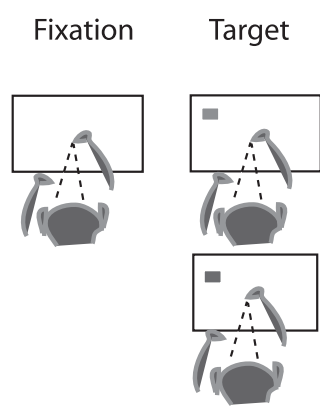

$500 \mathrm{~ms}$

c
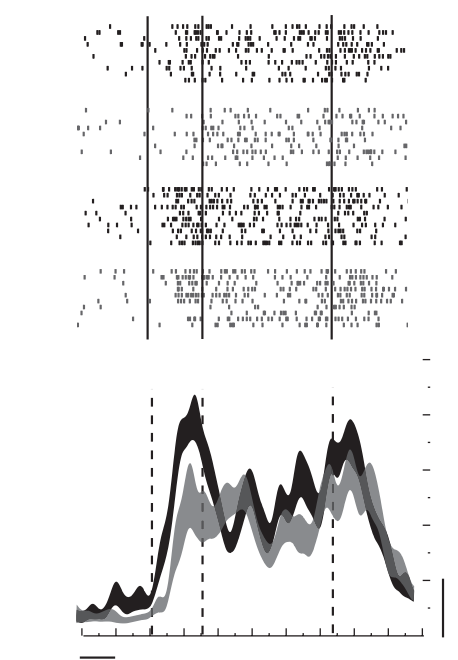

$200 \mathrm{msec}$
Delay

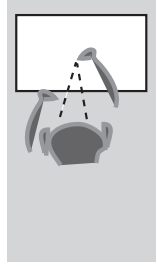

$800 \mathrm{~ms}$
Movement

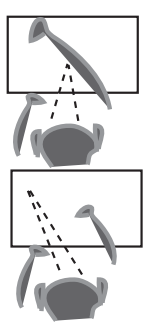

D
B

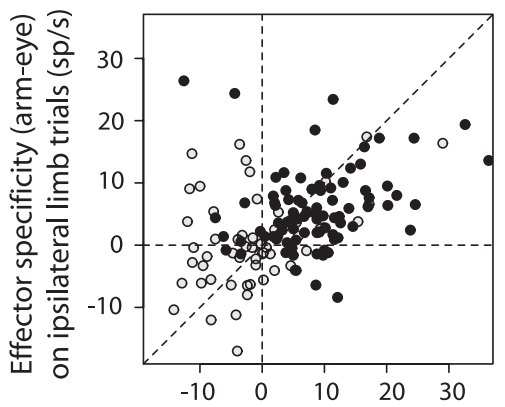

Effector specificity (arm-eye) on contralateral limb trials ( $\mathrm{sp} / \mathrm{s}$ )

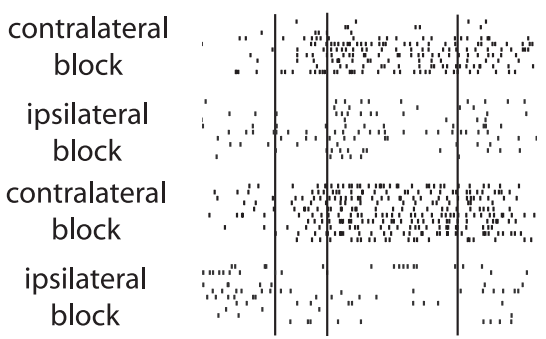

$10 \mathrm{sp} / \mathrm{s}$

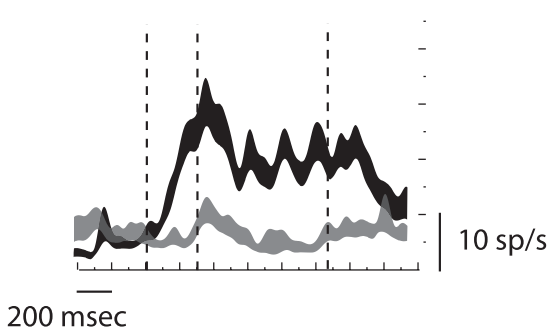

$200 \mathrm{msec}$

Figure 1. Behavioral task and single-unit responses. $A$, Memory task. A peripheral target (in green for reach and in red for saccade trials) instructs the spatial location and effector to be used (eyes or arm) for each trial. No stimulus was presented during the memory period. With the disappearance of the central fixation point (go signal), animals either reached or made saccadic eye movements to the remembered location of the target. Reach and saccade trials were randomly interleaved. $\boldsymbol{B}$, Effector specificity on contralateral-limb blocks (abscissa) versus ipsilateral-limb blocks (ordinate). Effector specificity was computed by subtracting the memory-period modulation on saccade versus reach trials within each limb block. Dark points distinguish cells that met our inclusion criteria ( 90 of 147 cells). C, An example bilateral-limb cell. D, An example contralateral-limb cell. Rasters are shown in the order they were collected, in four separate blocks (contralateral-limb trials in black and ipsilateral-limb trials in gray). Below the rasters, action potentials are summed over all contralateral- and ipsilateral-limb trials. Trace thickness represents mean \pm SEM. Overlaid vertical lines, in both rasters and summed action potentials, indicate target onset, target offset, and go signal.

tion in this way, signals not directly related to spatial tuning are eliminated (e.g., baseline differences in firing rate). We used two different criteria to classify cells as bilateral-, contralateral-, or ipsilaterallimb cells. The significance criterion assessed whether there was significant modulation with reaches made with either limb, with reaches made only with the contralateral limb, or with reaches made only with the ipsilateral limb $(p<0.05$, corrected for two comparisons, paired two-sided $t$ test). The index criterion assessed the contrast ratio of modulation evoked during reaches with either limb, and classified cells based on whether there was at least twice as much modulation for one arm compared with the other arm. The two criteria resulted in very similar results, as described in detail below.

Figure $2 B$ contrasts memory-period modulation on contralateral- and ipsilateral-limb trials for all 90 cells in our study. The majority of cells were modulated more before contralateral- compared with ipsilateral-limb reaches $(58 \%$ be-
Table 1. Behavioral performance

\begin{tabular}{|c|c|c|c|c|c|}
\hline & \multirow[b]{2}{*}{ Animal } & \multicolumn{2}{|c|}{ Memory task } & \multicolumn{2}{|c|}{ Cue-delay-target task } \\
\hline & & $\mathrm{RT}$ (ms) & Success rate (\%) & $\mathrm{RT}$ (ms) & Success rate (\%) \\
\hline \multirow[t]{2}{*}{ Contralateral limb } & G & $186(36)$ & $84(11)$ & $217(21)$ & $96(4)$ \\
\hline & 1 & $206(48)$ & $79(12)$ & $282(42)$ & $89(8)$ \\
\hline \multirow[t]{2}{*}{ Ipsilateral limb } & G & $194(41)$ & $85(11)$ & $193(18)$ & $98(3)$ \\
\hline & I & $198(41)$ & $84(10)$ & $250(35)$ & $94(7)$ \\
\hline \multirow[t]{2}{*}{ Saccade } & G & $169(23)$ & $92(8)$ & $158(14)$ & $99(2)$ \\
\hline & I & $172(25)$ & $79(15)$ & $160(14)$ & $93(9)$ \\
\hline
\end{tabular}

The values shown are the mean RTs across all trials, collapsed across the preferred and null directions, in the memory task or the cue-delay-target task and their SDs (in parentheses), followed by success rates and their SDs (in parentheses). low the diagonal line versus $42 \%$ above). Applying the significance criterion, we found significant memory-period modulation on both contralateral- and ipsilateral-limb trials in $49 \%$ of cells (light blue). One third (34\%) of cells showed significant modulation on contralateral- but not ipsilateral-limb trials (orange), and only one-sixth (17\%) showed significant modulation on ipsilateral- but not contralateral-limb trials (purple). Thus, memory activity, when present, was biased toward the contralateral limb: the number of cells significantly activated for 
A

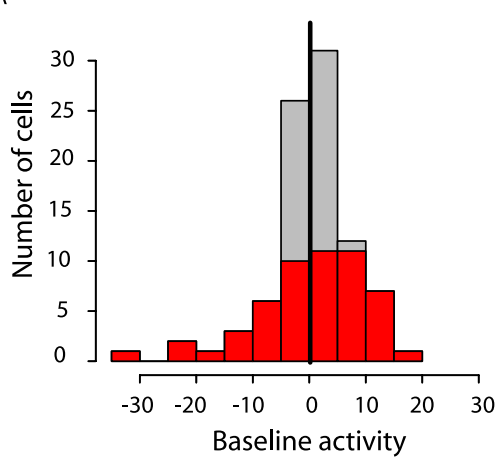

contralateral versus ipsilateral limb trials $(\mathrm{sp} / \mathrm{s})$

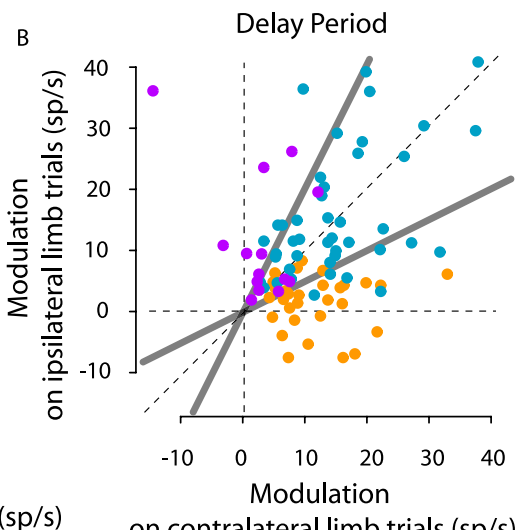

on contralateral limb trials (sp/s)

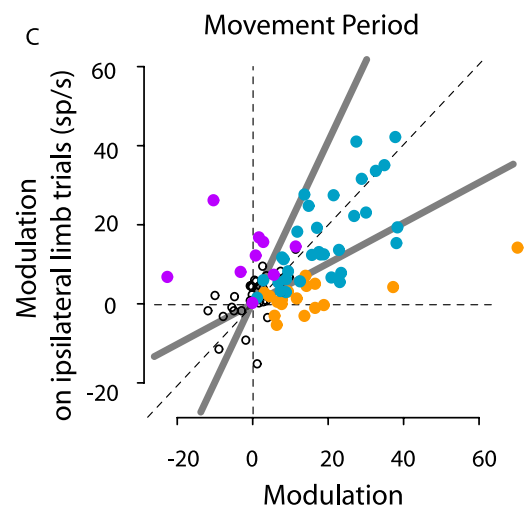

on contralateral limb trials (sp/s)
D

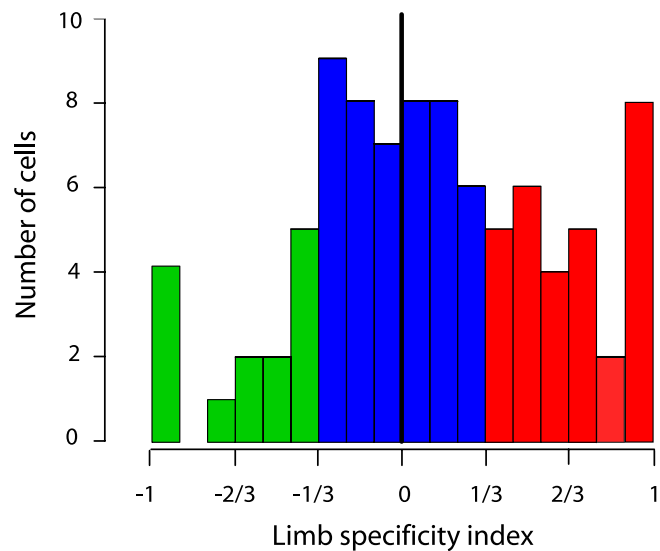

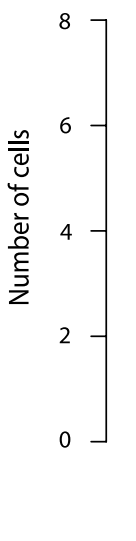

Movement Period

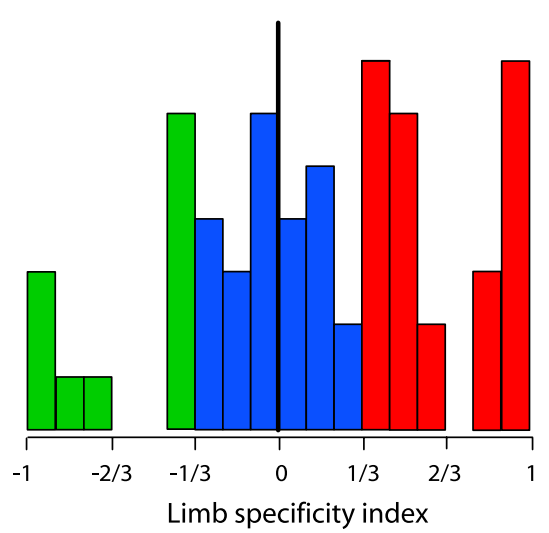

Figure 2. Limb specificity of PRR neurons. $A$, A comparison of baseline activity on contralateral-limb versus ipsilateral-limb trials. The cells with significant difference in baseline activity in two different limb blocks are shown in red. $\boldsymbol{B}, \boldsymbol{C}$, Scatter plots showing neuronal modulations on contralateral- versus ipsilateral-limb trials during the memory $(\boldsymbol{B})$ and the movement $(\boldsymbol{C})$ periods. (ells are classified according to the significance criterion (light blue, bilateral-limb cells; orange, contralateral-limb cells; purple, ipsilateral-limb cells). The open circles in C represent the cells that did not show significant movement response. Gray diagonal lines divide the plot into three segments using the ratios of $2: 1$ and 1:2 (contralateral limb:ipsilateral limb) as boundaries, showing how the cells are divided according to the index criterion. $\boldsymbol{D}, \boldsymbol{E}$, Histograms of limb-specificity indices (contrast ratios) during the memory period (D) and the movement period (E). Cells are color coded according to the index criterion (blue, bilateral-limb cells; red, contralateral-limb cells; green, ipsilateral-limb cells). Cells without significant movement responses $(n=30)$ are excluded from $\boldsymbol{E}$.

contralateral- but not ipsilateral-limb movements was twice as large as those showing the reverse pattern. [Cells without significant memory-period modulation for either limb were not included in the study (see Materials and Methods).]

Modulation during the time of the arm movement showed a bias toward the contralateral limb (Fig. 2C). Of those cells significantly active during the movement of at least one limb, 57\% were active for movements of either limb, 28\% were active only for the contralateral limb, and $15 \%$ were active only for the ipsilateral limb. These percentages are similar to those obtained during the memory period $(49,34$, and $17 \%$, respectively) and show once again that twice as many cells are strongly biased for the contralateral compared with the ipsilateral limb. Surprisingly, however, only one-third of cells fell in the same category during the memory and movement periods, and $33 \%$ of those cells active during the memory period were not significantly modulated during the movement period for either limb.

Figure 2, $D$ and $E$, shows limb specificity based on an index during contralateral- and ipsilateral-limb trials for the memory and movement periods, respectively (see Materials and Methods). Compared with a significance criterion, the limb-specificity index (index criterion) is continuous (from -1 to +1 ) rather than categorical and, therefore, provides a useful measure for comparing limb specificity across the population of cells. The distribution is biased toward the contralateral limb (mean index of 0.14 ; significantly different from 0 by Wilcoxon signed rank test, $p<0.05)$. Cells with at least twice as much modulation on contralateral- compared with ipsilateral-limb trials (specificity indices $>0.33$ ) were classified as contralateral-limb cells, those with at least twice as much modulation on ipsilateral- compared with contralateral-limb trials (specificity indices $<-0.33$ ) were classified as ipsilateral-limb cells, and the remainder were classified as bilateral-limb cells. These criteria result in cell counts nearly identical to those obtained using the significance criteria: 51,33, and 16\% for bilateral-, contralateral-, and ipsilateral-limb cells, respectively, for the memory period, and 40,42 , and $18 \%$, respectively, for the movement period. Once again, twice as many cells are strongly biased in favor of the contralateral limb compared with the ipsilateral limb. Consistent results were found when the two animals were considered individually, with $48 \%$ bilateral-, 37\% contralateral-, and 15\% ipsilateral-limb cells for monkey G, and 50, 30, and 20\% for monkey I (significance criterion, memory interval).

As a control, we asked whether memory activity during saccade trials was different in contralateral- versus ipsilateral-limb blocks. If, for example, isolation was systematically better on con- 

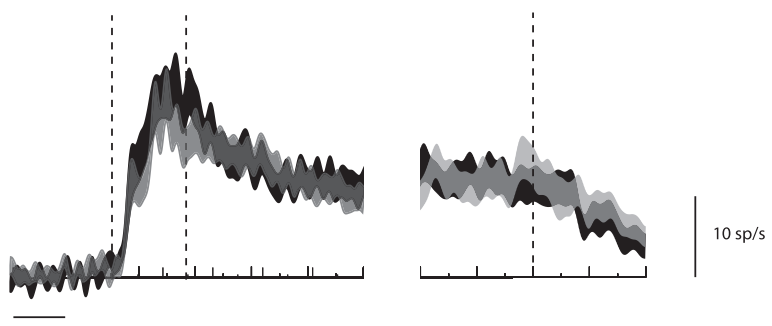

$200 \mathrm{msec}$
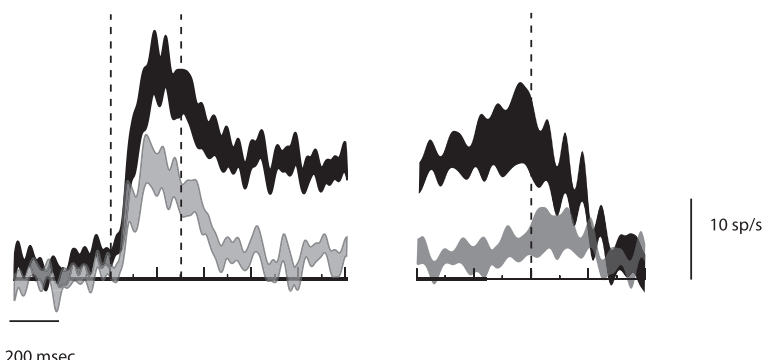

Figure 3. Time course of population responses. $\boldsymbol{A}, \boldsymbol{B}$, Bilateral-limb population time course $(n=46)(\boldsymbol{A})$ and contralateral-limb population $(n=30)(\boldsymbol{B})$. Population-averaged traces are shown as modulations (the difference in activity between the preferred and null direction trials). Action potentials are summed over all contralateral-and ipsilateral-limb trials. The trace thickness represents mean \pm SEM. The left side of each figure is aligned to target onset, whereas the right side is aligned to movement onset. Overlaid vertical lines indicate target onset, target offset, and movement onset.

tralateral blocks, or if postural signals caused by the initial limb configuration resulted in enhanced modulation (e.g., a gain field effect) in contralateral blocks, then we should also see a contralateral block bias in saccade trial memory activity. At the population level, there was no bias. Saccade memory activity was 1.00 spikes/s higher on ipsilateral-limb blocks compared with contralateral-limb blocks ( $p=0.18$, paired two-sided $t$ test). At the single-cell level there was also no bias. Nearly equal numbers of cells showed significant modulation $(p<0.05$, one-sided $t$ test) before a saccade in contralateral and ipsilateral blocks (19 cells showed significant modulation in both blocks, 7 only in contralateral blocks, and 9 only in ipsilateral blocks). Thus, whereas PRR cells showed a clear bias for higher memory-period activity before a reach during contralateral-limb blocks, there was no similar bias for saccades.

\section{Time course of responses}

Figure 3 contrasts population-averaged responses for reaches performed with the contralateral versus the ipsilateral limb. Bilateral-limb cells $(A)$ and contralateral-limb cells $(B)$ are shown separately. Bilateral-limb cells showed identical responses to movements with either limb. Our definition of these cells guaranteed that the mean memory-period response would be similar, but did not constrain the time courses to be so identical. For both limbs, there was an initial brisk transient response to the onset of the visual target, followed by sustained activity that persisted throughout the memory period, and no clear movement response. Contralateral-limb cells also showed a brisk transient re- sponse followed by sustained activity during contralateral-limb trials, but during ipsilateral-limb trials, there was almost no memory response and the initial transient response was only about half as large, diverging from the contralateral-limb trial response after $\sim 100 \mathrm{~ms}$. Whereas bilateral-limb cells showed absolutely no movement response at the population level, contralateral-limb cells showed an average increase of $2.23 \pm 4.06$ spikes/s during the $150 \mathrm{~ms}$ interval from $100 \mathrm{~ms}$ before movement onset compared with the memory period ( $p=0.59$, paired two-sided $t$ test).

\section{Spatial tuning for the contralateral and ipsilateral limbs}

To obtain the limb-specificity data just described, we first mapped the preferred direction for each cell using center-out movements of either the contralateral or ipsilateral limb, and then collected memory-guided reach data for each limb using only the preferred and opposite reach directions (see Materials and Methods). This procedure could lead to an incorrect conclusion if the preferred directions are not similar for the two limbs. Consider, for example, a cell that prefers rightward movements with the right arm, but leftward movements with the left arm. If we established the preferred direction for this cell while using the right arm, then we would erroneously conclude that the cell was strongly right-arm selective, because we would find strong responses in the preferred direction only when the right arm was being used. Similarly, if we instead established the preferred direction of the cell while using the left arm, we would erroneously conclude that the cell was strongly left-arm selective. In either case, our conclusion would be incorrect.

To directly determine whether PRR cells show similar preferred tuning directions for the two arms, we obtained full directional tuning curves for both the left and right arm from 45 cells. Because this required many trials per cell, we used visually guided reaches to make data collection more efficient (see Materials and Methods). Of the 45 cells, both the ipsilateral- and contralaterallimb tuning curves of 27 cells could be satisfactorily fit with a cosine. Tuning curves from an additional 12 cells could be fit for movements of just one limb or the other (nine contralateral limb only; three ipsilateral limb only), and six cells could not be fit for either limb. Figure $4 A$ shows the tuning curves for a typical cell. The fit amplitudes were 30.9 and 22.3 spikes/s, respectively, for reaches with the contralateral and ipsilateral limbs, and the phase difference between the two fitted curves was only $9.3^{\circ}$, which was not significantly different from zero ( $p=0.08$, bootstrap test).

Across the population, one-half of the 27 cells showed phase differences of $<20^{\circ}$, and $84 \%$ showed differences of $<60^{\circ}$; only five cells had phase differences significantly different from zero ( $p<0.05$, bootstrap test) (Fig. 4C). A small number of outliers showed large differences in tuning, but in these cells the fit for reaches with at least one limb tended to be poor (Fig. 4B) (7.1 spikes/s tuning amplitude for contralateral-limb reaches and 2.2 spikes/s for ipsilateral-limb reaches; $103.7^{\circ}$ phase difference). Finally, the distribution of tuning phases showed no significant systematic differences for the contralateral versus the ipsilateral limb ( $p<0.05$, Watson's two-sample test of homogeneity). We conclude that the large fraction of limb-dependent cells that we observe in PRR cannot be explained by differences in tuning for reaches with the contralateral versus ipsilateral limb.

To confirm that the population of cells tested in Figure $4 C$ resembled the cells in our larger population, we used the amplitude of the cosine fits to calculate limb-specificity indices (Fig. $4 D$ ). As with the cells tested in the delayed movement paradigm, the distribution was positively skewed toward the contralateral 
limb (median index of $0.12 ; p<0.05$, Wilcoxon signed rank test), with $43 \%$ bilateral-, 38\% contralateral-, and 17\% ipsilateral-limb cells. This not only shows that the tested cells resembled the general population, but also confirms that the contralateral-limb bias exists when modulations are calculated without assuming identical preferred directions for the two limbs.

\section{Limb specificity is not determined by preferred direction}

Limb specificity in PRR could reflect the preferred direction of each cell. If there is a bias to reach for targets with the closest limb, then cells with preferred directions in the contralateral visual hemifield might be most active for reaches with the contralateral limb, cells with ipsilateral preferred directions might be most active for reaches with the ipsilateral limb, and cells with preferred directions near the midline might be unbiased. However, this was not the case. PRR cells had contralateral, ipsilateral, and midline preferred directions $(40,43$, and $17 \%$ of our sample, respectively), but there was no correlation between preferred direction and preferred limb (Fig. 5). For example, nearly equal numbers of contralateral-limb cells had contralateral and ipsilateral preferred directions (12 and 13, respectively), and the same was true for ipsilateral-limb cells ( six on each side). The only marked asymmetry was independent of limb preference: $62 \%$ of cells had preferred directions in the lower visual field, but only $10 \%$ had preferred directions in the upper visual field.

\section{Cell types are not anatomically distinct}

If bilateral-limb cells and contralateral-limb cells form two separate populations and do not simply reflect opposite ends of a continuum, then they might also be anatomically distinct. To examine this, we reconstructed the locations of cells relative to the cortical anatomy. Figure $6 \mathrm{~A}$ shows a descending series of horizontal MRI slices overlaid with the locations of all the bilateral- and contralateral-limb cells from monkey G. The two cell types, recorded mostly on the medial bank of the posterior IPS, were interleaved along the cortex and, when tested quantitatively (see Materials and Methods), showed no evidence of independent clustering ( $p>0.2$ for each individual monkey or combined data). Thus, the anatomy provides no support for two distinct populations of cells.

\section{Bilateral-limb cells do not lead contralateral-limb cells}

Regardless of whether limb-dependent and limb-independent neurons constitute separate populations or two ends of a continuum of cell types within a single population, it is possible that information may be transferred from the limb-independent cells to limb-dependent cells, that is, from those cells unaffected by which limb will actually move, and therefore putatively further from the motor output, to those cells that encode which limb will move, and therefore putatively closer to the motor output. As an
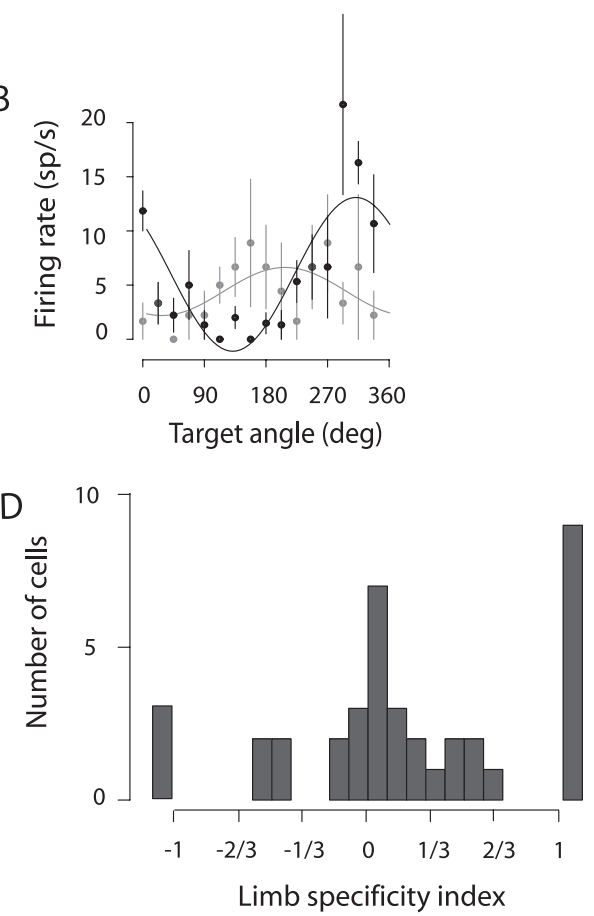

Limb specificity index

Figure 4. Spatial tuning between contralateral and ipsilateral limbs. A, A typical example cell. The tuning curves (target angle limb-specificity indices from the directional tuning task, computed as a contrast ratio of the amplitudes of the cosine fits for each $\mathrm{mb}$. The outermost bars represent those cells in which the fit was successful only with the contralateral limb (to the right of 1) or the left of -1$)$. Error bars in $A, B$ indicate SEM.

alternative to this serial relationship, limb-dependent and limbindependent neurons may constitute parallel channels that transmit different types of information more or less independently. In the serial but not in the parallel processing scenario, the activity from limb-independent cells would drive the activity of limbdependent cells. We tested these two alternatives by examining neuronal latencies to the initial appearance of the target in the memory task (Fig. 7). We found no statistically significant lead of bilateral-limb cell responses $(132 \pm 48 \mathrm{~ms}$, median \pm SEM; $n=$ 46) compared with contralateral-limb cell responses $(126 \pm 47$ $\mathrm{ms} ; n=30)$ using either a Wilcoxon signed rank test $(p=0.64)$ or a Kolmogorov-Smirnov test $(p=0.67)$ (Fig. $7 A)$. Furthermore, overlaid population traces from the two types of cells showed no difference in their initial rising responses to the target (Fig. 7B). Thus, we find no evidence for a serial feedforward connection between the two cell types. Although not conclusive, the data are consistent with bilateral- and contralateral-limb cells receiving information in parallel.

\section{PRR activity predicts the RT of contralateral- but not ipsilateral-limb movements}

A recent study shows that PRR activity in the preparation period just before a reach target appears is inversely correlated with the subsequent reach RT (Snyder et al., 2006). We used the same design as Snyder et al. (2006) to compare the influence of PRR activity on reaches made with the contralateral and ipsilateral limbs, and to determine whether these influences are similar for both bilateral-limb and contralateral-limb cells. In particular, we hypothesized that bilateral-limb cells would show an effect of 


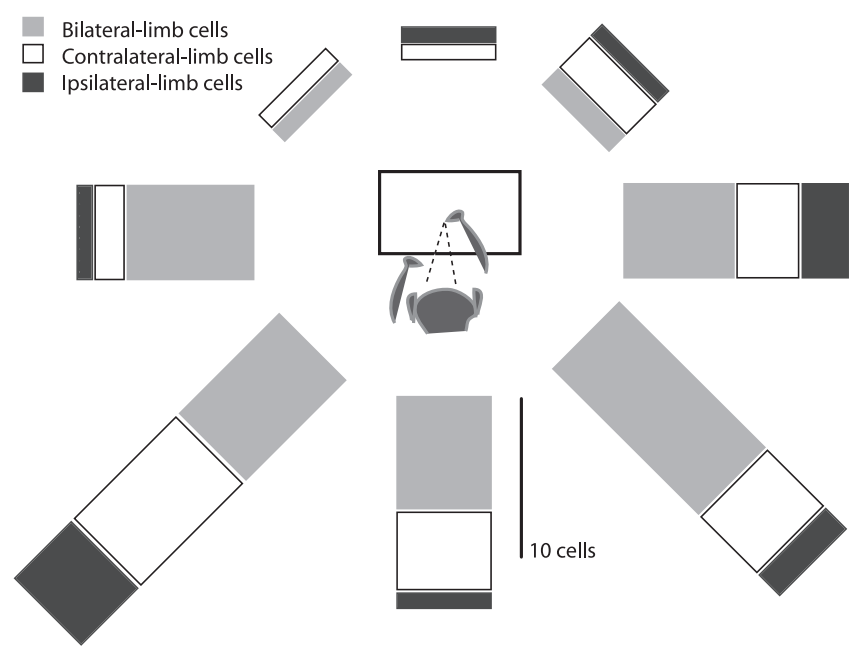

Figure 5. Cell types and preferred directions. A comparison between cell types and preferred directions determined by the directional mapping task. The eight bars arranged in a circle represent the number of bilateral-limb cells, contralateral-limb cells, and ipsilateral-limb cells for each corresponding preferred direction. The bars on the right represent preferred directions in the visual field ipsilateral to the recorded neuron, and the bars on the left represent contralateral preferred directions. The eccentricity of the target location is not represented.

firing rate on reach RT for movements of either limb, whereas contralateral-limb cells would show an effect only for movements of the contralateral limb.

We started by replicating the results of the previous study, which was performed in the same two animals but using data from different recording sessions. We tested a total of 76 cells in the cue-delay-target task, in which reach or saccade instruction was given before target location, separated by a variable delay period (Fig. 8). Behavioral performance during collection of these data is shown in Table 1. For each cell, we collected the data in the preferred and null directions. Because the nonspatial response to the effector instruction before target onset is independent from where the animals would reach (Snyder et al., 2006), we pooled across the preferred and null directions to analyze the data. Figure $8 B$ shows the relationship between activity and RT on contralateral- (left) and ipsilateral-limb trials (right) for a single cell. The activity of this cell was correlated with RT on contralateral-limb trials $(r=-0.37 ; p<0.05$, Pearson's correlation), but not on ipsilateral-limb trials $(r=0.07 ; p=0.65)$. The activity on reach trials was significantly greater than on saccade trials (difference of 2.76 spikes/s; $p<0.00001$, paired two-sided $t$ test). The activity across the population of 76 cells was reliably correlated with contralateral-limb RT but not with ipsilaterallimb RT. The mean Pearson's correlation coefficients $(r)$ were -0.09 and +0.03 , respectively $(p<0.005$ and $p=0.39$, Wilcoxon signed rank test) during the $300 \mathrm{~ms}$ pretarget interval. The activity on saccade trials was not correlated with saccade RT ( $r=$ $0.002 ; p=0.76$ ), indicating that the effect is specific to reaches and not to some nonspecific factor, such as arousal level, affecting all sensorimotor transformations.

Of the 76 cells, 40 cells met our PRR criteria for the current study (i.e., showed significant visual and memory activity in the memory task) (see Materials and Methods). In these cells, the activity on reach trials was significantly greater than on saccade trials (difference of 3.53 spikes/s; $p<0.0001$ ). The activity across the population of 40 cells was reliably correlated with contralateral-limb RT but not with ipsilateral-limb RT. The mean Pearson's correlation coefficients were -0.08 and +0.01 , respectively $(p<0.05$ and $p=0.9)$ during the $300 \mathrm{~ms}$ pretarget interval. Again, PRR activity was not correlated with saccade RT $(r=0.02 ; p=0.62)$.

Next, we tested contralateral- and bilateral-limb cells separately. Based on the index criterion, 21 of the 40 cells were classified as bilateral-limb cells, 13 as contralateral, and 6 as ipsilateral. Using the significance criterion yielded counts of 22,10 , and 8 , respectively. Figure $9 A$ shows histograms of the correlation coefficients from individual bilateral- and contralateral-limb cells $(n=34)$. On contralateral-limb trials (Fig. 9A, left), correlation coefficients were negatively skewed for both contralateral-limb cells (gray bars) (mean $r=-0.19$; one-sided Wilcoxon signed rank test) and bilateral-limb cells (black bars) (mean $r=-0.09$ ), indicating that higher PRR activity is correlated with faster (shorter) reach RT ( $p<0.05$ for both populations separately and when combined; mean combined $r=-0.08$; $p<0.0001)$. In contrast, neither contralateral-limb cells $(r=0.02)$ nor bilaterallimb cells $(r=-0.03)$ showed an effect on ipsilateral-limb trials (Fig. 9A, right) (all $p$ values $>0.5$ ). Even ipsilateral-limb cell activity $(n=6)$ was uncorrelated with ipsilateral-limb RT $(r=0.08$; $p=0.31$; higher firing was, if anything, associated with slower reach $\mathrm{RT}$ ). These results did not depend on the method of cell classification. When we used the significance criterion rather than the index criterion to classify cells, we obtained very similar results, for example, bilateral-limb cell activity was correlated with contralateral reach RT $(r=-0.15$; $p<0.0005)$ but not ipsilateral reach RT $(r=-0.03 ; p=0.46)$.

Figure $9 B$ shows the relationship between the limb-specificity index (abscissa) and the correlation coefficient between firing rate and RT (ordinate). On contralateral-limb trials (black bars), cells with larger limb-specificity indices (that is, cells with higher activity before a reach with the contralateral compared with the ipsilateral-limb trials) showed stronger correlations between firing rate and reach RT (solid black line) (slope not equal to zero, $p<0.05$ ). In contrast, we did not observe any correlation on ipsilateral-limb trials (solid gray line) (slope not significantly different from zero, $p=0.66$ ). In summary, PRR activity is correlated with RTs of the contralateral but not ipsilateral limb.

\section{Discussion}

The present study suggests that PRR neurons are involved in goal-directed reaching to a remembered or visible target in a limb-specific manner. In particular, our data support the idea that PRR neurons play a more significant role in planning contralateral than ipsilateral-limb movements. Consistent with previous work (Snyder et al., 1997, 1998; Batista et al., 1999; Buneo et al., 2002; Calton et al., 2002; Quian Quiroga et al., 2006), PRR neurons were modulated when the target for an upcoming movement was situated in the preferred direction of the cell. In this study, we explored whether this modulation depends on whether the animal intends to reach with the contralateral or ipsilateral limb. Single-unit recording revealed that one-half of the PRR neurons that are visually responsive and show memory-period activity were modulated during reach planning and execution without regard for which limb was to be engaged. One-third of neurons were modulated much more strongly or exclusively during the planning and execution of movements of the contralateral limb. Only one-sixth of neurons were modulated more strongly or exclusively by the planning and execution of ipsilateral-limb movements. Many (59\%) PRR neurons showed a significant difference in baseline firing during contralateral- compared with ipsilateral-limb blocks, although the effect was small and not significantly biased toward either arm at the population level. 
The contralateral-limb bias seen in the present study is unlikely to reflect the training history of the animals. Both monkeys were first trained to reach using the right (ipsilateral) limb $\sim 7$ years before the current data were collected. One animal spontaneously switched to the left limb after $\sim 4$ years, whereas the other animal continued to use the right. Finally, both animals were extensively trained on interleaving limbs before data collection. Both now show a similar contralateral-limb bias in PRR.

The contralateral-limb bias is also not likely to reflect a general difference in state while performing in a contralateral- compared with ipsilateral-limb block. The evidence for this is that activity on saccade trials was no different in the two block types. There was also no systematic difference in baseline activity between the two blocks.

The fact that a cell fires during a particular behavior is consistent with, but does not establish a functional role in, that behavior. The firing rates of PRR neurons immediately before the appearance of a visual target are inversely related to the reach RT to that target (Snyder et al., 2006). Because this relationship occurs for contralateral-limb movements but not ipsilateral-limb movements or saccades, it is unlikely to reflect a nonspecific correlation (e.g., the state of arousal), and instead supports a functional role for PRR neurons in visually guided reaching. In particular, the findings suggest that PRR neurons convey visual spatial information regarding a putative reaching target to downstream neurons. In the present study, we replicated these results on an independent data set and then used the same methodology to compare contralateral- and ipsilateral-limb reaching.

As a population, the firing rates of contralateral-limb PRR neurons (neurons that showed at least twice as much modulation when planning or executing reaches with the contralateral compared with the ipsilateral limb) were inversely related to the RT of contralateral- but not ipsilateral-limb movements. Surprisingly, the same was true for bilateral-limb cells. Despite showing clear increases in firing when the animal planned or executed a reach with the ipsilateral limb, the neuronal firing rate immediately before the appearance of a reaching target had no relationship with the RT of the ipsilateral-limb movement. Therefore, based on our RT data, PRR activity is functionally linked to contralateral-limb movements but not to ipsilateral-limb movements.

The RT correlation is present regardless of whether the reach is in the preferred or nonpreferred direction, and yet there is no correlation between firing rate and a subsequent saccadic RT. Thus, the data indicate that the influence of increased PRR activity immediately before the appearance of a visual stimulus is reach specific but not spatially specific. This may seem puzzling. PRR neurons are spatially tuned, and the facilitory effect of increased firing in neurons tuned in one direction might be expected to be canceled out by increased firing in neurons tuned in the opposite direction. However, cancellation would occur only in a linear push-pull model in which signals are "read out" as the difference between neuron/antineuron pairs (Robinson, 1989;
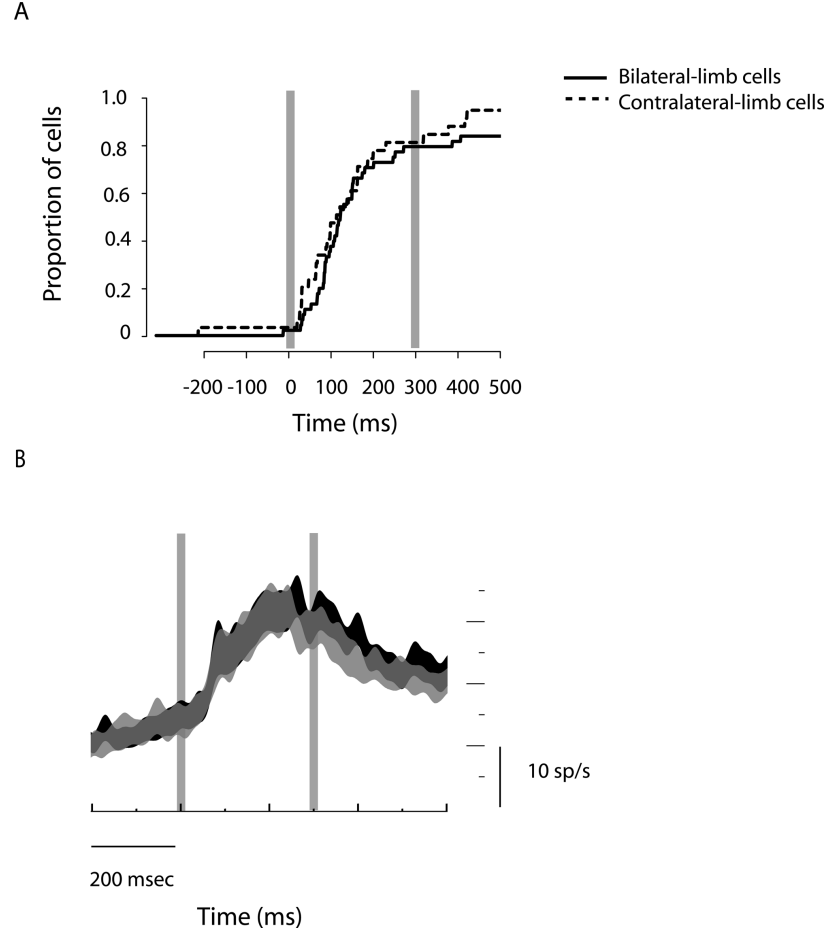

Figure 7. Neuronal latency between bilateral-limb and contralateral-limb cells. $\boldsymbol{A}, \mathrm{A}$ cumulative histogram of neuronal latencies of bilateral-limb cells (solid line) and contralateral-limb cells (dotted line) to target onset in the memory task. $\boldsymbol{B}$, Population-averaged time courses of the target response are shown separately for bilateral-limb cells (black) and contralateral-limb cells (gray) on contralateral-limb trials. Overlaid vertical lines indicate the times of target onset and offset. The thickness of traces shows mean \pm SEM.

Shadlen et al., 1996). Such a model is clearly appropriate in some cases (e.g., vestibular canal signals) and in other cases can provide a useful simplification. However, it is not clear that this model applies to all systems. Indeed, the fact that parietal neurons are 
A.

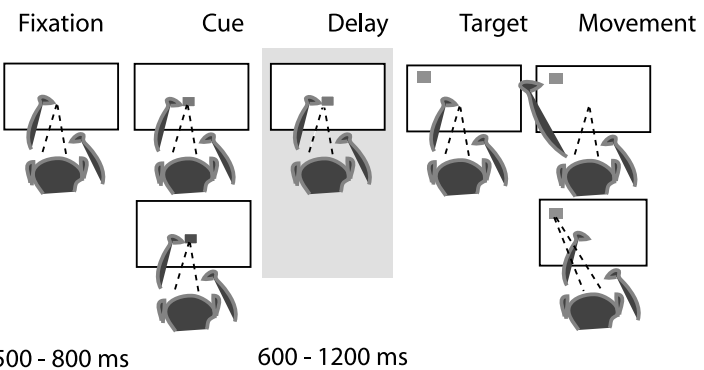

B.

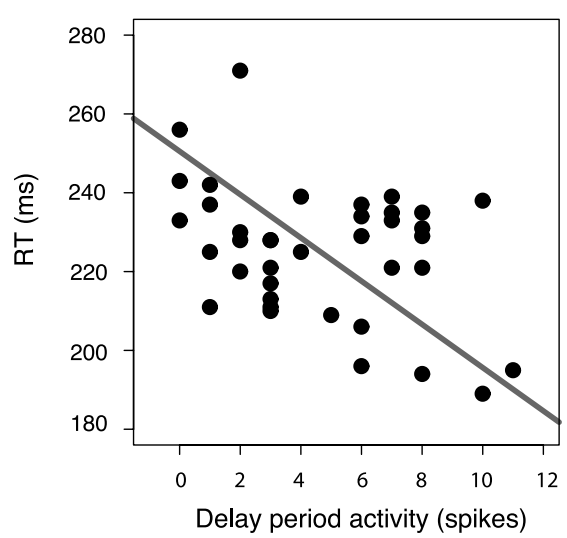

Ipsilateral limb

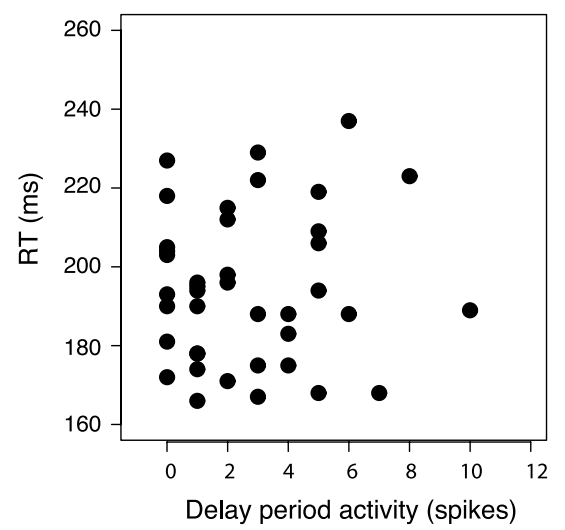

Figure 8. The cue-delay-target task. $\boldsymbol{A}$, After a variable delay after fixating at the center, the central fixation point changed its color to nonspatially instruct whether it would be a reach (in green) or a saccade (in red) trial. After a variable delay, a target of a neutral color (in gray) appeared in the periphery. Animals were free to make movements once the target appeared. Reach and saccade trials were randomly interleaved. $\boldsymbol{B}$, A single-cell example of the relationship between activity (spikes in the last $300 \mathrm{~ms}$ before target onset on reach trials) and RT (milliseconds). Dots show individual trials on contralateral-limb (left) and ipsilaterallimb trials (right). The gray line through the data points (left) is a type-II regression line.

generally greatly excited by targets that fall inside the receptive field (RF) and only slightly inhibited by targets falling outside (Snyder et al., 1997) suggests that this system is not push-pull. In a system that does not use a strict neuron/antineuron readout, increasing the firing rate of all neurons before the appearance of a spatial stimulus may well have a facilitory effect on the entire system.

It is possible that PRR is driven by spatial inputs that are not themselves limb-specific, and that specificity is conferred only by virtue of the downstream connections of PRR. In this view, one might argue that PRR contains a high-level spatial representation and not a limb-specific movement-planning signal per se. However, this distinction may be merely semantic, reflecting whether one chooses to characterize a representation based on the signals that give rise to it (the inputs to the representation) or based on the role it plays in behavior (the outputs of the representation). The fact that the representation is itself (incompletely) biased toward the contralateral limb, and influences the contralateral limb more strongly than the ipsilateral limb, suggests that the best semantic description might be that of a signal intermediate between the transformation from a high-level spatial representation and a limb-specific movement-planning signal.

\section{Potential roles of the activity on ipsilateral-limb trials}

Why might PRR neurons be modulated on ipsilateral-limb trials at all if that modulation has no influence on the RT of ipsilaterallimb movements? One possibility is that, even on trials in which the animal is cued to prepare an ipsilateral-limb movement, a plan to move the contralateral limb may nonetheless be generated. This secondary plan might reflect preparation for some-

thing unexpected. For example, the reach with the ipsilateral limb might become suddenly blocked, or a second limb might need to be brought into play. This is analogous to the suggestion that low levels of activity in PRR on saccade trials, intermediate levels of activity in lateral intraparietal area (LIP) on reach trials, and high levels of activity in area 5 on "no go" trials, may reflect "contingency plans" for a movement that has not been specifically instructed or has even been explicitly ruled out, but for which the animal nonetheless prepares (Kalaska and Crammond, 1995; Snyder et al., 1997; Calton et al., 2002). Behavior on error trials often indicates that even movements that have been explicitly ruled out may nonetheless still be performed, albeit at very low rates. Thus, it is not implausible that some representation of these alternative movements persists, even on correct trials. If it is indeed common for movements that are not cued and often not executed to nonetheless be represented in the cortex, then our interpretations of the functions of particular cortical areas may have to be revised.

There are at least two alternative explanations for our findings. Bilateral-limb neurons might play a role in movements of the ipsilateral limb in a way that does not influence the response time to a suddenly appearing target. For this reason, it would be useful to test for functional specialization in other tasks and using other performance measures. One way to do this is with reversible lesions. A previous study found that permanent V6a lesions produce deficits specific to the contralateral limb, including increases in reach RT (Battaglini et al., 2002). In contrast, another study reported that permanent bilateral lesions in areas 5, 7b, and MIP produce incorrect reaching in the dark, but have little effect on visually guided reaching (Rushworth et al., 1997). It would be worthwhile to repeat these studies using reversible lesions, thus avoiding the confound of long-term adaptation to the lesion.

Alternatively, the activity observed on ipsilateral-limb trials might be linked to coordinating the two forelimbs in space. Coordinating movement of the two limbs may require that signals related to both be present in the same neuron. Many neurons in PMd, M1, and the supplementary motor area (SMA) are suggested to be involved in coordinated bimanual movements (Donchin et al., 1998, 2002; Kermadi et al., 1998, 2000). Accumulating evidence suggests that the neural mechanisms for bimanual coordination may be distinct from the neural mechanisms of controlling a single limb (Tanji et al., 1988; Donchin et al., 1998, 2002; Kermadi et al., 2000). In PRR, contralateral-limb cells might be involved in moving a single limb, while bilateral-limb cells might play a role in bimanual coordination. This alternative explanation is consistent with our neuronal latency results (Fig. 7) supporting separate and parallel pathways (as opposed to a single serial pathway) for information flow in bilateraland unilateral-limb cells.

Comparisons with previous studies on limb specificity: PPC Several previous studies have found evidence for bilateral representations with a contralateral bias in parietal areas. Kermadi et 
al. (2000) recorded from a small number of cells in an unspecified portion of the PPC and found cells that responded to movements of one or both limbs, with many more neurons responding to contralateral-limb movements than ipsilateral movements. However, reach targets were not aligned to each cell's preferred direction, which complicates the interpretation of the data in the context of visually guided reach planning.

A recent study shows that cells in area LIP are modulated when an animal is visually cued to release a handle, with greater modulation for the contralateral compared with the ipsilateral limb (Oristaglio et al., 2006). It is unclear to what extent this reflects a role in visually guided reaching behavior. Activity is most prominent when the cue to release the handle is presented within the LIP RF, but no movement (of either the eyes or the arm) is explicitly directed toward that cue.

Neurons in intermediate and highlevel parietal somatosensory areas (e.g., areas 2 and 5, including cells on the medial bank of the IPS, anterior to PRR) show a strong bias for having a RF on the contralateral side, although many cells have bilateral RFs on the hands and other body parts (Iwamura et al., 1994; Taoka et al., 1998). These areas may contribute proprioceptive information about contralateral and ipsilateral limb position to PRR as part of the transformation of visual information into reach plans. Such interactions between somatosensory and visual signals have been described in areas that overlap with PRR. For example, neurons in caudal Brodmann area 5 (PEc) (Pandya and Seltzer, 1982) located in the posterior part of the superior parietal lobule show a strong contralateral-limb bias after somatosensory stimulation to the limbs (Breveglieri et al., 2006). A subgroup of these PEc neurons respond to both visual and somatosensory stimuli (Breveglieri et al., 2008). Many neurons in MIP that respond to somatosensory stimulation also show a contralateral-limb bias in visually guided reaching (Colby and Duhamel, 1991). It has also been suggested that area 5 responses to visual targets may be driven, in part, by input from PRR (Buneo et al., 2002; Buneo and Andersen, 2006). Overall, it seems clear that limb-related information in the parietal cortex is neither strictly contralateral nor strictly bilateral, and this property may reflect an intermediate stage of the sensorimotor transformation.

Human PPC resembles monkey with respect to limb specificity. Most functional imaging studies have reported that blood oxygen level-dependent (BOLD) signals are elevated bilaterally in response to pointing movements of the fingers of either arm, but that the modulation is stronger for contralateral movements (Sereno et al., 2001; Astafiev et al., 2003; Connolly et al., 2003; Medendorp et al., 2003, 2005; Merriam et al., 2003; Beurze et al., 2007). This pattern is very similar to what we have observed in monkeys when we recorded neuronal action potentials. Similar to the RT data in the current study in monkeys, tests of functional significance using transcranial magnetic stimulation (TMS) in humans also reveals lateralized deficits in reaching (Desmurget et al., 1999) and grasping (Rice et al., 2007). [But see the study by Vesia et al. (2006), who found bilateral deficits with TMS stimulation, where the particular deficit depended on whether stimulation was applied to the left or right hemisphere.] Thus, in both humans and monkeys, there is bilateral organization based on evoked activity (spikes or BOLD) but contralateral organization based on measures of functional significance (correlation between activity and movement kinematics or perturbation). We hypothesize that, in both monkeys and in humans, PPC is involved in generating contralateral-limb movements, and that activity reflecting a potential contralateral-limb movement is formed even when the task demands only an ipsilateral reach.

\section{Comparisons with previous studies on limb specificity: frontal cortex}

Like PPC, frontal regions often respond to movements of either limb, with larger responses for contralateral- than ipsilaterallimb movements. Contralateral biases are quite strong in the primary motor cortex (Donchin et al., 1998; Kermadi et al., 1998; Hoshi and Tanji, 2002, 2006; Cisek et al., 2003), with smaller but nonetheless clear biases in the premotor cortex (Cisek et al., 2003; Hoshi and Tanji, 2006). Within premotor cortex, the ventral subdivision (PMv) emphasizes visuospatial information, whereas the dorsal division (PMd), like PRR, encodes both visuospatial information about the target and the arm to be used in an upcoming reach (Boussaoud and Wise, 1993; Hoshi and Tanji, 2006). In particular, visual spatial information is represented more strongly in the rostral portion of $\mathrm{PMd}$, whereas effector information (which arm is to be used) is represented more strongly in the caudal portion (Shen and Alexander, 1997; Lebedev and Wise, 2001; Cisek et al., 2003; Hoshi and Tanji, 2006). 
PRR neurons likely project more extensively to caudal PMd than to rostral PMd (Matelli et al., 1998) (see below).

Consistent with having different functional characteristics, PMd and PMv receive different projections from PPC. Neurons from medial IPS areas (e.g., MIP and V6a) project to PMd, whereas ventral and lateral areas [e.g., VIP (ventral intraparietal area), AIP (anterior intraparietal area), and LIP] project to PMv (Kurata, 1991; Caminiti et al., 1996; Johnson et al., 1996; Matelli et al., 1998; Luppino et al., 1999; Tanne-Gariepy et al., 2002). These projection patterns suggest that there might be a distinct dorsal pathway from the medial IPS to PMd that primarily, but not exclusively, transmits effector information, and a ventral pathway from the ventral and lateral IPS to PMv that primarily, but not exclusively, transmits visuospatial information. Like PRR, PMd shows similar spatial tuning for movements with either arm (Cisek et al. 2003). Hoshi and Tanji (2006) suggest that PMd neurons combine information about spatial target location with the instruction to reach with either the contralateral or ipsilateral limb. Based on the current data, it seems likely that this process in fact occurs in both PRR and PMd.

A subpopulation of PMd cells, termed "potential-response cells," are active when an upcoming movement has been signaled but not yet fully specified (Cisek and Kalaska, 2005). This is reminiscent of current and previous findings that some PPC neurons encode "nonpreferred" movements (e.g., ipsilateral-limb movements in PRR) (Kalaska and Crammond, 1995; Snyder et al., 1997). Thus, activities in parietal and premotor circuits for visually guided reaching do not slavishly correlate only with an upcoming "instructed" action, that is, not all activity in PPC and PMd leads directly to a behavioral response. Instead, targets are represented in these circuits even when an upcoming movement is merely a possibility. In other words, an encoded motor plan does not necessarily lead to a decoded motor plan in the parietalfrontal circuits involved in the sensorimotor transformation.

\section{Conclusion}

In the present study, we provide novel evidence that PRR neurons in the primate PPC are specifically involved in the planning of contralateral-limb movements. Some cells are modulated during planned movements of the contralateral limb, others during planned movements of either limb, and still others during planned movements of the ipsilateral limb. Despite this heterogeneity in evoked responses, we find that the firing rates of both contralateral and bilateral cell subpopulations are specifically related to contralateral-limb RT and not to ipsilateral-limb RT. We suggest that the PPC functions as a limb-dependent intermediate stage when transforming sensory information (target location) into a motor plan for visually guided reaching.

\section{References}

Andersen RA, Snyder LH, Bradley DC, Xing J (1997) Multimodal representation of space in the posterior parietal cortex and its use in planning movements. Annu Rev Neurosci 20:303-330.

Astafiev SV, Shulman GL, Stanley CM, Snyder AZ, Van Essen DC, Corbetta M (2003) Functional organization of human intraparietal and frontal cortex for attending, looking, and pointing. J Neurosci 23:4689-4699.

Batista AP, Buneo CA, Snyder LH, Andersen RA (1999) Reach plans in eyecentered coordinates. Science 285:257-260.

Battaglini PP, Muzur A, Galletti C, Skrap M, Brovelli A, Fattori P (2002) Effects of lesions to area V6A in monkeys. Exp Brain Res 144:419-422.

Beurze SM, de Lange FP, Toni I, Medendorp WP (2007) Integration of target and effector information in the human brain during reach planning. J Neurophysiol 97:188-199.

Boussaoud D, Wise SP (1993) Primate frontal cortex: neuronal activity following attentional versus intentional cues. Exp Brain Res 95:15-27.
Breveglieri R, Galletti C, Gamberini M, Passarelli L, Fattori P (2006) Somatosensory cells in area PEc of macaque posterior parietal cortex. J Neurosci 26:3679-3684.

Breveglieri R, Galletti C, Monaco S, Fattori P (2008) Visual, somatosensory, and bimodal activities in the macaque parietal area PEc. Cereb Cortex $18: 806-816$

Buneo CA, Andersen RA (2006) The posterior parietal cortex: sensorimotor interface for the planning and online control of visually guided movements. Neuropsychologia 44:2594-2606.

Buneo CA, Jarvis MR, Batista AP, Andersen RA (2002) Direct visuomotor transformations for reaching. Nature 416:632-636.

Calton JL, Dickinson AR, Snyder LH (2002) Non-spatial, motor-specific activation in posterior parietal cortex. Nat Neurosci 5:580-588.

Caminiti R, Ferraina S, Johnson PB (1996) The sources of visual information to the primate frontal lobe: a novel role for the superior parietal lobule. Cereb Cortex 6:319-328.

Cisek P, Kalaska JF (2005) Neural correlates of reaching decisions in dorsal premotor cortex: specification of multiple direction choices and final selection of action. Neuron 45:801-814.

Cisek P, Crammond DJ, Kalaska JF (2003) Neural activity in primary motor and dorsal premotor cortex in reaching tasks with the contralateral versus ipsilateral arm. J Neurophysiol 89:922-942.

Cohen YE, Andersen RA (2000) Reaches to sounds encoded in an eyecentered reference frame. Neuron 27:647-652.

Cohen YE, Batista AP, Andersen RA (2002) Comparison of neural activity preceding reaches to auditory and visual stimuli in the parietal reach region. NeuroReport 13:891-894.

Colby CL, Duhamel JR (1991) Heterogeneity of extrastriate visual areas and multiple parietal areas in the macaque monkey. Neuropsychologia 29:517-537.

Colby CL, Gattass R, Olson CR, Gross CG (1988) Topographical organization of cortical afferents to extrastriate visual area PO in the macaque: a dual tracer study. J Comp Neurol 269:392-413.

Connolly JD, Andersen RA, Goodale MA (2003) FMRI evidence for a "parietal reach region" in the human brain. Exp Brain Res 153:140-145.

Desmurget M, Epstein CM, Turner RS, Prablanc C, Alexander GE, Grafton ST (1999) Role of the posterior parietal cortex in updating reaching movements to a visual target. Nat Neurosci 2:563-567.

Donchin O, Gribova A, Steinberg O, Bergman H, Vaadia E (1998) Primary motor cortex is involved in bimanual coordination. Nature 395:274-278.

Donchin O, Gribova A, Steinberg O, Mitz AR, Bergman H, Vaadia E (2002) Single-unit activity related to bimanual arm movements in the primary and supplementary motor cortices. J Neurophysiol 88:3498-3517.

Galletti C, Fattori P, Kutz DF, Battaglini PP (1997) Arm movement-related neurons in the visual area V6A of the macaque superior parietal lobule. Eur J Neurosci 9:410-413.

Galletti C, Fattori P, Kutz DF, Gamberini M (1999) Brain location and visual topography of cortical area V6A in the macaque monkey. Eur J Neurosci 11:575-582.

Hoshi E, Tanji J (2000) Integration of target and body-part information in the premotor cortex when planning action. Nature 408:466-470.

Hoshi E, Tanji J (2002) Contrasting neuronal activity in the dorsal and ventral premotor areas during preparation to reach. J Neurophysiol 87:1123-1128.

Hoshi E, Tanji J (2006) Differential involvement of neurons in the dorsal and ventral premotor cortex during processing of visual signals for action planning. J Neurophysiol 95:3596-3616.

Iwamura Y, Iriki A, Tanaka M (1994) Bilateral hand representation in the postcentral somatosensory cortex. Nature 369:554-556.

Johnson PB, Ferraina S, Bianchi L, Caminiti R (1996) Cortical networks for visual reaching: physiological and anatomical organization of frontal and parietal lobe arm regions. Cereb Cortex 6:102-119.

Kalaska JF, Crammond DJ (1995) Deciding not to GO: neuronal correlates of response selection in a GO/NOGO task in primate premotor and parietal cortex. Cereb Cortex 5:410-428.

Kalaska JF, Scott SH, Cisek P, Sergio LE (1997) Cortical control of reaching movements. Curr Opin Neurobiol 7:849-859.

Kermadi I, Liu Y, Tempini A, Calciati E, Rouiller EM (1998) Neuronal activity in the primate supplementary motor area and the primary motor cortex in relation to spatio-temporal bimanual coordination. Somatosens Mot Res 15:287-308.

Kermadi I, Liu Y, Rouiller EM (2000) Do bimanual motor actions involve 
the dorsal premotor (PMd), cingulate (CMA) and posterior parietal (PPC) cortices? Comparison with primary and supplementary motor cortical areas. Somatosens Mot Res 17:255-271.

Kurata K (1991) Corticocortical inputs to the dorsal and ventral aspects of the premotor cortex of macaque monkeys. Neurosci Res 12:263-280.

Lebedev MA, Wise SP (2001) Tuning for the orientation of spatial attention in dorsal premotor cortex. Eur J Neurosci 13:1002-1008.

Lewis JW, Van Essen DC (2000a) Corticocortical connections of visual, sensorimotor, and multimodal processing areas in the parietal lobe of the macaque monkey. J Comp Neurol 428:112-137.

Lewis JW, Van Essen DC (2000b) Mapping of architectonic subdivisions in the macaque monkey, with emphasis on parieto-occipital cortex. J Comp Neurol 428:79-111.

Luppino G, Murata A, Govoni P, Matelli M (1999) Largely segregated parietofrontal connections linking rostral intraparietal cortex (areas AIP and VIP) and the ventral premotor cortex (areas F5 and F4). Exp Brain Res 128:181-187.

Matelli M, Govoni P, Galletti C, Kutz DF, Luppino G (1998) Superior area 6 afferents from the superior parietal lobule in the macaque monkey. J Comp Neurol 402:327-352.

Medendorp WP, Goltz HC, Vilis T, Crawford JD (2003) Gaze-centered updating of visual space in human parietal cortex. J Neurosci 23:6209-6214.

Medendorp WP, Goltz HC, Crawford JD, Vilis T (2005) Integration of target and effector information in human posterior parietal cortex for the planning of action. J Neurophysiol 93:954-962.

Merriam EP, Genovese CR, Colby CL (2003) Spatial updating in human parietal cortex. Neuron 39:361-373.

Muakkassa KF, Strick PL (1979) Frontal lobe inputs to primate motor cortex: evidence for four somatotopically organized "premotor" areas. Brain Res 177:176-182.

Oristaglio J, Schneider DM, Balan PF, Gottlieb J (2006) Integration of visuospatial and effector information during symbolically cued limb movements in monkey lateral intraparietal area. J Neurosci 26:8310-8319.

Pandya DN, Seltzer B (1982) Intrinsic connections and architectonics of posterior parietal cortex in the rhesus monkey. J Comp Neurol 204:196210.

Quian Quiroga R, Snyder LH, Batista AP, Cui H, Andersen RA (2006) Movement intention is better predicted than attention in the posterior parietal cortex. J Neurosci 26:3615-3620.

Rice NJ, Tunik E, Cross ES, Grafton ST (2007) On-line grasp control is mediated by the contralateral hemisphere. Brain Res 1175:76-84.

Robinson DA (1989) Integrating with neurons. Annu Rev Neurosci 12:33-45.
Rushworth MF, Nixon PD, Passingham RE (1997) Parietal cortex and movement. I. Movement selection and reaching. Exp Brain Res 117:292-310.

Sakata H, Taira M, Kusunoki M, Murata A, Tanaka Y, Tsutsui K (1998) Neural coding of 3D features of objects for hand action in the parietal cortex of the monkey. Philos Trans R Soc Lond B Biol Sci 353:1363-1373.

Sereno MI, Pitzalis S, Martinez A (2001) Mapping of contralateral space in retinotopic coordinates by a parietal cortical area in humans. Science 294:1350-1354.

Shadlen MN, Britten KH, Newsome WT, Movshon JA (1996) A computational analysis of the relationship between neuronal and behavioral responses to visual motion. J Neurosci 16:1486-1510.

Shen L, Alexander GE (1997) Preferential representation of instructed target location versus limb trajectory in dorsal premotor area. J Neurophysiol 77:1195-1212.

Snyder LH, Batista AP, Andersen RA (1997) Coding of intention in the posterior parietal cortex. Nature 386:167-170.

Snyder LH, Batista AP, Andersen RA (1998) Change in motor plan, without a change in the spatial locus of attention, modulates activity in posterior parietal cortex. J Neurophysiol 79:2814-2819.

Snyder LH, Dickinson AR, Calton JL (2006) Preparatory delay activity in the monkey parietal reach region predicts reach reaction times. J Neurosci 26:10091-10099.

Tanji J, Okano K, Sato KC (1988) Neuronal activity in cortical motor areas related to ipsilateral, contralateral, and bilateral digit movements of the monkey. J Neurophysiol 60:325-343.

Tanne J, Boussaoud D, Boyer-Zeller N, Rouiller EM (1995) Direct visual pathways for reaching movements in the macaque monkey. NeuroReport 7:267-272.

Tanne-Gariepy J, Rouiller EM, Boussaoud D (2002) Parietal inputs to dorsal versus ventral premotor areas in the macaque monkey: evidence for largely segregated visuomotor pathways. Exp Brain Res 145:91-103.

Taoka M, Toda T, Iwamura Y (1998) Representation of the midline trunk, bilateral arms, and shoulders in the monkey postcentral somatosensory cortex. Exp Brain Res 123:315-322.

Vesia M, Monteon JA, Sergio LE, Crawford JD (2006) Hemispheric asymmetry in memory-guided pointing during single-pulse transcranial magnetic stimulation of human parietal cortex. J Neurophysiol 96:3016-3027.

Wise SP, Boussaoud D, Johnson PB, Caminiti R (1997) Premotor and parietal cortex: corticocortical connectivity and combinatorial computations. Annu Rev Neurosci 20:25-42. 